\title{
Neurofibromatosis: Types 1 and 2
}

\author{
S. Borofsky and L.M. Levy
}

\section{ABSTRACT}

SUMMARY: Neurofibromatosis types 1 and 2 are a group of neurocutaneous syndromes resulting from disorders in cell regulation. Despite sharing a common name, neurofibromatosis types 1 and 2 are quite distinct phakomatoses, both clinically and genetically.

ABBREVIATIONS: NF-1 = neurofibromatosis type 1; NF-2 = neurofibromatosis type 2; MAPK = ras/mitogen-activated protein kinase pathway

$\mathrm{N}$ eurofibromatosis type 1 is seen in 1 of $3000-5000$ people across the world. ${ }^{1}$ This disease was first described in 1882 by von Recklinghausen, leading to the initial name of the condition, von Recklinghausen disease. The condition is manifested by a constellation of neurocutaneous tumors and vasculitis. Neurofibromatosis type 2 is a less common condition, seen in approximately 1 in 50,000 individuals and is characterized more often by central nervous system tumors. ${ }^{2}$ The purpose of this vignette is to compare and contrast the manifestations and genetic backgrounds of these 2 entities.

\section{WHAT ARE THE CLINICAL MANIFESTATIONS OF NEUROFIBROMATOSIS TYPE 1?}

Cutaneous neurofibromas are the most common manifestation of NF-1 and are seen in nearly every adult with this condition. Other common findings include plexiform tumors, optic gliomas, Lisch nodules (hamartomatous nodules in the iris), and café au lait macules. Additional manifestations can include learning disabilities, attention deficit/hyperactivity disorder, and vasculopathies. While cutaneous tumors related to this condition are most often benign, malignant degeneration and vasculopathy can occur, leading to early death. Plexiform tumors have a higher risk of degeneration, with malignancy occurring in approximately $10 \%$ of tumors. ${ }^{3,4}$ Benign gliomas occur in $15 \%$ of patients with NF-1; and though most follow an indolent course, larger lesions can cause significant morbidity.

Received January 13, 2013; accepted after revision January 22

From the Department of Radiology, George Washington University Medical Center, Washington, DC

Please address correspondence to Lucien M. Levy, MD, PhD, Professor of Radiology and Director of Neuroradiology, George Washington University Medical Center, 901 23rd St NW, Washington, DC 20037; e-mail: llevy@mfa.gwu.edu

http://dx.doi.org/10.3174/ajnr.A3534

\section{WHAT ARE THE CLINICAL MANIFESTATIONS OF NEUROFIBROMATOSIS TYPE 2?}

The classic feature of neurofibromatosis type 2 is bilateral vestibular schwannomas, which occur in up to $95 \%$ of patients with the disorder. Schwannomas can involve other cranial nerves, most frequently III and $\mathrm{V}^{2}$ As such, the most common presenting clinical symptoms include hearing loss, dizziness, headaches, diplopia, and facial weakness. CNS tumors, including meningiomas and gliomas, are frequent occurrences in patients with NF-2. Multiple meningiomas are noted to occur in $50 \%-60 \%$ of these patients. ${ }^{7}$ Spinal tumors, most frequently ependymomas, are other common manifestations involving approximately $90 \%$ of patients with NF-2. One-third of patients with spinal ependymomas are at risk for spinal cord compression. ${ }^{8}$ Patients with NF-2 can also have cutaneous neurofibromas, though to a much lesser extent than in NF-1.

\section{WHAT IS THE NORMAL FUNCTION OF THE NF1 GENE?}

NF1 is a tumor-suppressor gene encoded by chromosome 17q11.2, extending 283 kilobases. ${ }^{9}$ Normally, the NF1 gene encodes the protein neurofibromin, which is an inhibitor of the ras/mitogen-activated protein kinase pathway. This pathway is an important regulator of cellular growth and differentiation. The specific role of neurofibromin involves aiding the dephosphorylation of ras guanosine triphosphate. ${ }^{10}$

\section{WHAT IS THE FUNCTION OF THE NF2 GENE?}

NF2 also encodes a tumor-suppressor gene on chromosome 22q12.2, extending 110 kilobases. Normally, this gene codes for the protein merlin, a regulator of cell growth, especially in Schwann cells. Merlin is quite atypical for a tumor-suppressor gene because it localizes to the cell membrane for regulation. Merlin acts as a cytoskeletal linker, interacting with multiple membrane proteins to regulate cell growth, motility, and remodelling. 
Normally, merlin inhibits multiple intracellular pathways, including the MAPK signaling pathway (which is also involved in NF1). ${ }^{4}$ A key method by which merlin inhibits cell growth is via contact-dependent inhibition. ${ }^{7}$

\section{HOW DOES AN NF1 MUTATION CAUSE DISEASE?}

NF1 is thought to cause disease by following characteristics of the "two-hit hypothesis," first described by Alfred Knudson in 1971. All patients with NF1 are heterozygous for the NF1 mutation, and it is thought that somatic mutations lead to the development of tumors by causing a loss of heterozygosity. ${ }^{11}$ The mutation most often results in truncation of neurofibromin, though $>500$ types of mutations have been described. ${ }^{5}$ While the precise mechanisms are still being discovered, current hypotheses support the notion that a somatic mutation results in a "second hit," leading to a loss in regulation of the cell cycle and resultant tumors. For instance, melanocytes cultured from café au lait macules were found to exhibit a somatic mutation in the NF1 cell, implying that a loss of heterozygosity resulted in these lesions. However, the occurrence of tumors in Schwann cells, fibroblasts, neurons, epithelial cells, and perineural cells suggests that the condition may also originate from NF1 mutations in multipotent precursor cells that give rise to these elements. ${ }^{10}$

\section{HOW DOES AN NF2 MUTATION CAUSE DISEASE?}

Similar to those of NF1, NF2 mutations follow the "two-hit hypothesis," in which tumor formation begins when both alleles of the gene are inactivated. The first hit is from a de novo or germline mutation, and the second hit results in a loss of heterozygosity and in truncation of merlin, leading to abnormal function. In patients with abnormal merlin, Schwann cells cannot form stable adherens junctions; this deficit leads to a loss of contact-dependent inhibition. The loss of inhibition results in abnormal cell growth via multiple unregulated intracellular pathways.

\section{WHAT ARE THE GENETICS OF NF-1?}

Neurofibromatosis type 1 exhibits autosomal dominant transmission. Half of the patients with NF-1 inherit the mutation from their parents, while the other half develop the mutation de novo. The disease exhibits $100 \%$ penetrance, though the extent of symptoms varies widely among individuals. ${ }^{10}$

\section{WHAT ARE THE GENETICS OF NF-2?}

Neurofibromatosis type 2 also exhibits autosomal dominant transmission. Patients either inherit the gene via autosomal dominant transmission from their parents or develop the mutation de novo. Like neurofibromatosis type 1 , de novo mutations are common because many patients with the disease have no family his- tory. ${ }^{12}$ Twenty to thirty percent of patients may exhibit mosaicism, resulting in mild disease or localized or unilateral tumors. ${ }^{8}$

\section{WHAT IS THE ROLE OF RADIOLOGY IN THESE CONDITIONS?}

MR imaging findings of neurofibromatosis type 1 include identification of focal areas of T2 hyperintensity, often in the brain stem, cerebellum, and basal ganglia. Pilocytic astrocytomas, brain stem gliomas, plexiform neurofibromas, and orbital gliomas are easily diagnosed and localized with the use of MR imaging. However, routine MR imaging screening for patients with clinically diagnosed NF-1 remains controversial. ${ }^{5}$ Those in favor claim that MR imaging can diagnose potentially debilitating tumors before they become clinically evident. Those opposed argue that clinical treatment is rarely affected and note the necessity of sedation for some children and the high cost of MR imaging.

Conversely, routine MR imaging screening is always indicated for patients with NF-2, given the high prevalence of CNS tumors. ${ }^{7}$ Contrast-enhanced MR imaging for NF-2 with gadolinium with thin sections through the brain stem is optimal for the identification of vestibular schwannomas. Cervical spine MR imaging is also suggested for the evaluation of spinal tumors, most commonly ependymomas.

\section{REFERENCES}

1. Solomon K, Warren E, Dombi N, et al. Automated detection and volume measurement of plexiform neurofibromas in neurofibromatosis 1 using magnetic resonance imaging. Comput Med Imaging Graph 2004;28:257-65

2. Chan JW. Neuro-ophthalmic features of the neurocutaneous syndromes. Int Ophthalmol Clin 2012;52:73-85

3. Van Meerbeeck SF, Verstraete KL, Janssens S, et al. Whole body MR imaging in neurofibromatosis type 1. Eur J Radiol 2009;69:236-42

4. Asthagiri AR, Parry DM, Butman JA, et al. Neurofibromatosis type 2. Lancet 2009;373:1974-86

5. Jett K, Friedman JM. Clinical and genetic aspects of neurofibromatosis 1. Genet Med 2010;12:1-11

6. Ullrich NJ, Raja AI, Irons MB, et al. Brainstem lesions in neurofibromatosis type 1. Neurosurgery 2007;61:762-66

7. Hanemann CO. Magic but treatable? Tumours due to loss of merlin. Brain 2008;131(pt 3):606-15

8. Ferner RE. The neurofibromatosis. Pract Neurol 2010;10:82-93

9. Laycock-van Spyk S, Thomas N, Cooper DN, et al. Neurofibromatosis type 1-associated tumours: their somatic mutational spectrum and pathogenesis. Hum Genomics 2011;5:623-90

10. Jouhilahti EM, Peltonen S, Heape AM, et al. The pathoetiology of neurofibromatosis 1. Am J Pathol 2011;178:1932-39

11. Legius E, Marchuk D, Collins F, et al. Somatic deletion of the neurofibromatosis type 1 gene in a neurofibrosarcoma supports a tumor suppressor gene hypothesis. Nat Genet 1993;3:122-26

12. Curto M, McClatchey AI. Nf2/Merlin: a coordinator of receptor signalling and intercellular contact. Br J Cancer 2008;98:256-62 